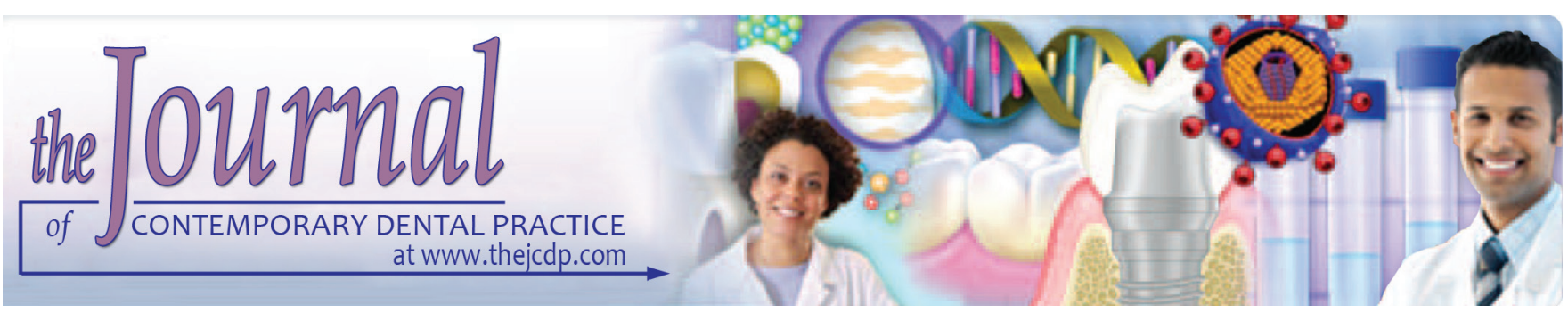

\title{
A Radiographic Classification for Retrograde Peri-implantitis
}

\author{
${ }^{1}$ Rucha Shah, ${ }^{2}$ Raison Thomas, ${ }^{3}$ AB Tarun Kumar, ${ }^{4}$ Dhoom Singh Mehta
}

\begin{abstract}
Background: Retrograde peri-implantitis (RPI) is an inflammatory disease that affects the apical part of an osseointegrated implant, while the coronal portion of the implant sustains a normal bone-to-implant interface. It is a diagnostic and therapeutic dilemma for implantologists. There is lack of a standard classification system and a definite treatment algorithm for the same. This article aims to introduce a classification system for RPI based on the radiographic amount of bone loss around an implant apex.
\end{abstract}

Materials and methods: A search of PubMed database was conducted with the keywords "retrograde peri-implantitis" and "implant periapical lesion." Preoperative intraoral periapical (IOPA) radiographs of implants with RPI in case reports/case series were compiled. A total of 54 IOPAs from 36 articles were compiled and were assessed.

Results: Three different classes were proposed. The amount of bone loss from the apex of the implant to the most coronal part of radiolucency was calculated as a percentage of the total implant length and classified into one of the three classes: Mild, moderate, and advanced. Treatment options and prognosis have been suggested for each class.

Conclusion: The proposed classification may allow for an easy and reproducible radiographic assessment of the RPI lesion and may serve as a guideline to prognosis and treatment planning.

Keywords: Implant, Periapical implant bone loss, Periapical infection.

How to cite this article: Shah R, Thomas R, Kumar ABT, Mehta DS. A Radiographic Classification for Retrograde Periimplantitis. J Contemp Dent Pract 2016;17(4):313-321.

Source of support: Nil

Conflict of interest: None

${ }^{1-4}$ Department of Periodontics, Bapuji Dental College and
Hospital, Davangere, Karnataka, India

Corresponding Author: Rucha Shah, Lecturer, Department of Periodontics, Bapuji Dental College and Hospital, Davangere Karnataka, India, Phone: +917676279879, e-mail: srucha2k@ yahoo.com

\section{INTRODUCTION}

Dental implants have revolutionized the field of dentistry. Since the era of Brånemark, vast improvements have been made in our understanding of dental implant physiology and biology. Similar to natural teeth, implants are also susceptible to plaque biofilm formation and subsequent soft tissue and bone destruction. The most common inflammatory lesion of dental implant is peri-implantitis. The term was first suggested by Mombelli et $\mathrm{al}^{1}$ and several classifications for the same exist. ${ }^{2-4}$ Another separate entity "retrograde peri-implantitis (RPI)" was first introduced by McAllister et al in 1992. ${ }^{5}$ It was described as a "clinically symptomatic periapical lesion that develops within the first few months after implant insertion while the coronal portion of the implant sustains a normal bone to implant interface." Retrograde peri-implantitis is a relatively rare clinical entity and there is a paucity of scientific literature on this topic. ${ }^{6,7}$ The etiology is not clear but most of the cases show bacterial infection. The management of this lesion is mainly empirical and may include open-flap debridement, guided bone regeneration, implant apical resection, or explantation.

Till date, there is no uniformly accepted definition or classification of RPI. A previous classification has been proposed by Reiser and Nevins, ${ }^{8}$ who classified RPI as either inactive or infected lesions. Sussman 9 classified RPI into two types based on the origin of the lesion: Type 1 -implant to tooth, which occurs during osteotomy preparation either by direct trauma or through indirect damage, which causes the adjacent pulp to undergo devitalization, and type $2-$ tooth to implant, which occurs shortly after the placement of the implant when an adjacent tooth develops a periapical pathology, either by operative damage to the pulp or through reactivation of a prior apical lesion. PeñarrochaDiago et $\mathrm{al}^{10}$ classified the RPI lesion according to the stages in which it involves into acute nonsuppurated apical peri-implantitis, acute suppurated apical peri-implantitis, 
or subacute or suppurated fistulized apical peri-implantitis. They also suggested treatment guidelines for all the stages. A periodontal, implant, separate, and traumatic (PIST) classification has been proposed by Kadkhodazadeh and Amid, ${ }^{11}$ which has combined peri-implant, periodontal, and periapical lesions. The degree of bone loss around the implant apex may influence the choice of treatment and prognosis of RPI. None of the existing classifications classify RPI according to the severity of involvement. Also, no guidelines are present regarding the prognosis for the same.

A reproducible quantitative classification is much more objective and has several benefits. It aids in the determination of relatively more accurate and standardized diagnosis and prognosis. A quantitative classification considering the degree of bone destruction around an implant is not present. Such classifications already exist for periodontitis and peri-implantitis. ${ }^{2,12}$ A standard case definition enables the estimation of true prevalence of any condition. While analyzing different treatment modalities, a baseline standard classification system may give a better guideline so as to assess which treatment modality is more effective. It can be expected that the severity of involvement is one of the main factors that can dictate the type of treatment and prognosis of a case. Thus, this classification was based on the severity of involvement.

The aim of this article is to introduce a classification for RPI quantitatively based on the radiographic amount of bone destruction seen for mild, moderate, and advanced grades of RPI.

\section{MATERIALS AND METHODS}

\section{Literature Search}

An electronic literature search was done in the PubMed database. The keywords used were "retrograde periimplantitis (RPI)" and "implant periapical lesion (IPL)." The search was performed in December 2015 and all results thus, obtained were included. The total number of hits using RPI was 22 and using IPL was 76. After removal of duplicates $(n=8), 89$ results were obtained. The search hits were then screened for clear relevance by an analysis of the title and abstract by two reviewers. A total of 56 articles were considered. ${ }^{6-11,13-62}$ A total of 33 articles were excluded as being not relevant. ${ }^{63-95}$ Those articles not in the English language were excluded $(n=1) .{ }^{40}$ Full text of rest of the articles was sought. Seven were not available as full text, and hence were not included. 9,27,28,32,46,59,62 Another article was excluded as it was an animal study $(\mathrm{n}=1) .{ }^{56}$ The process is demonstrated in Flow Chart 1.

From the articles for which full text was available, images of high-quality intraoral periapical (IOPA) radiographs of the implant having RPI immediately after diagnosis were obtained. Twelve of the articles were excluded as they had no IOPAs of the lesion. .,11,24,25,33,35,37-39,45,48,53 A total of
Flow Chart 1: Process for selection of articles for proposed classification

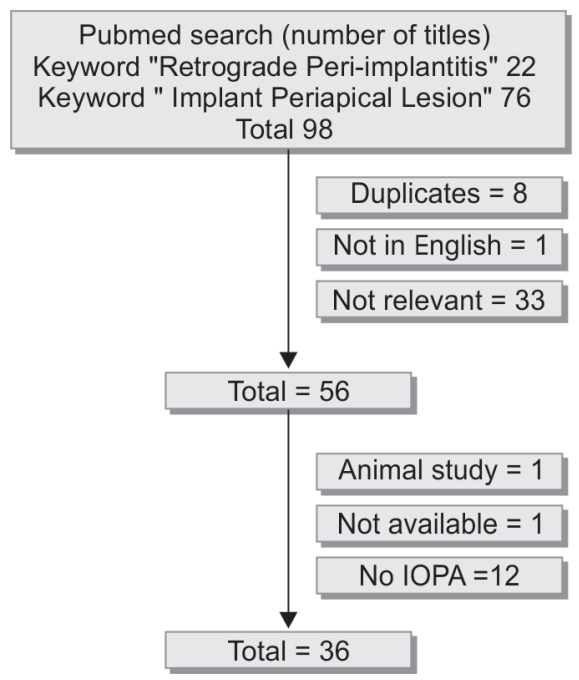

54 IOPAs from 36 articles were compiled. One periodontist (SR) and one implantologist (TAB) independently analyzed the IOPAs. The proposed classification was prepared keeping in mind several requirements as previously described. ${ }^{63}$ The requirements were for it to be comprehensive enough to include all possible periapical lesions around the dental implant, to be simple, logical, reasonable, and reproducible. It should be acceptable, have ease of application, should be scientifically based (by considering all the recently published literature), and should be helpful to determine the prognosis and treatment guidelines. ${ }^{11}$ After several sessions of discussion, consensus regarding the radiological classification was reached and the following classification was proposed. Also, wherever the treatment protocol was mentioned, it was recorded against the type of treatment given in different class.

\section{Radiographic Classification of RPI}

To classify the RPI lesions, bone loss was measured in an apico-coronal direction from the apex of the implant to the most coronal point of extension of bone loss in millimeters. The derived value was then calculated as a percentage of the radiographic implant length (Fig. 1A). The bone loss around the implant may or may not involve both the implant surfaces (medial and distal) (Figs 1B to 1D). Depending on this percentage, the observed bone loss was assigned into one of the three categories:

1. Mild lesion (class I) is characterized by radiographic bone loss that extends to $<25 \%$ of the implant length from the implant apex (Fig. 2A).

2. Moderate lesion (class II) is characterized by radiographic bone loss between 25 and $50 \%$ of the implant length as measured from the implant apex (Fig. 2B).

3. Advanced lesion (class III) is characterized by radiographic bone loss extending to $>50 \%$ of the implant length from the implant apex (Fig. 2C). 


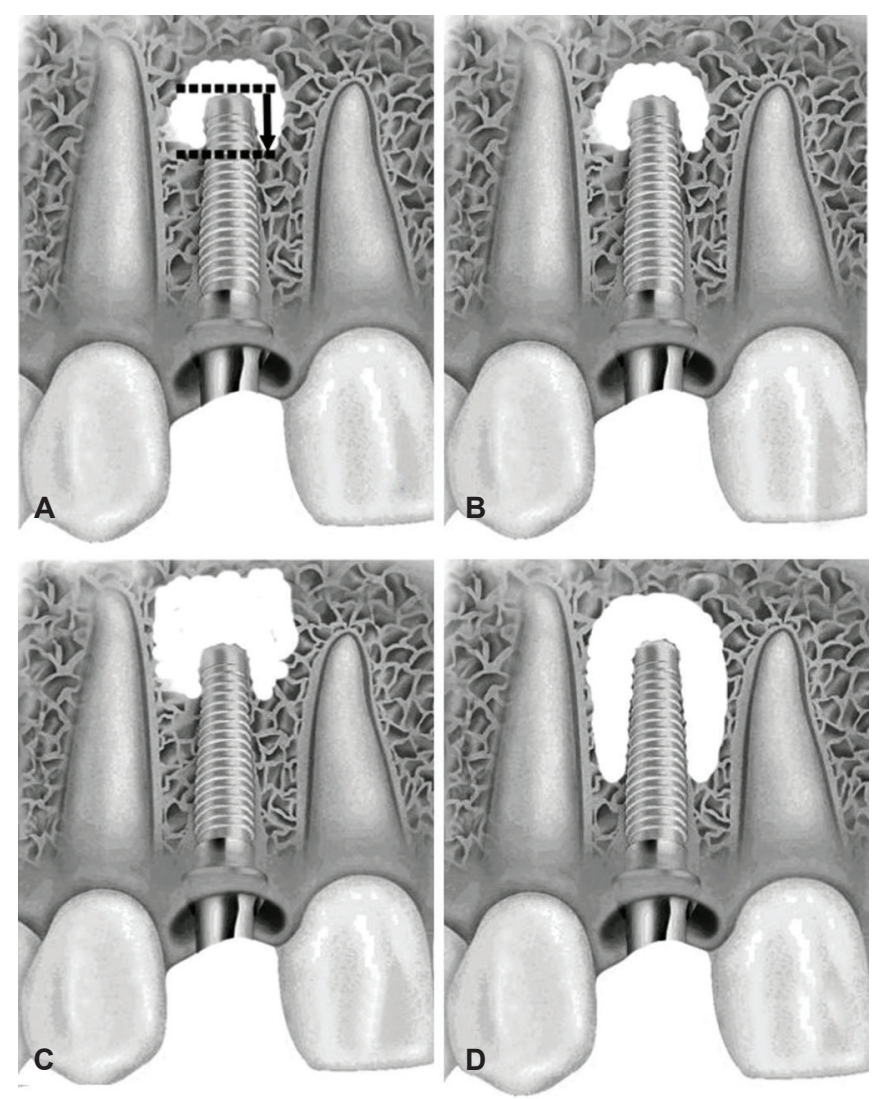

Figs 1A to D: The method to classify a retrograde peri-implantitis lesion: (A) Measurement of bone loss (measure the length marked in arrow and divide by the radiographic total length of implant), ( $B$ and $C$ ) Both these lesions would be classified as class I ( $\%$ bone loss is $<25 \%$ in both scenario), and (D) Even though the apical extension of lesion is same as in Figure B, this is class III lesion as percentage of involved implant is more than $50 \%$

\section{Statistical Analysis}

The statistical analysis was done using Statistical Package for the Social Sciences (SPSS) software version 16.0. The frequency of observation of each class was also calculated. Interexaminer variation was assessed using Cohen $\mathrm{K}$ values.

\section{RESULTS}

In the classification agreement of the evaluators, the $\mathrm{K}$ value was found to be 0.67 , which can be considered as a good agreement. The distribution of the different classes is demonstrated in Table 1 . The most commonly encountered classification is class II.

Table 1: Proposed classification of retrograde periodontitis

\begin{tabular}{|c|c|c|}
\hline Classification & Stage & Amount of bone loss \\
\hline Class I & Mild & $\begin{array}{l}\text { Extends }<25 \% \text { of the implant } \\
\text { length from implant apex }\end{array}$ \\
\hline Class II & Moderate & $\begin{array}{l}25-50 \% \text { of the implant length } \\
\text { from implant apex }\end{array}$ \\
\hline Class III & Advanced & $\begin{array}{l}>50 \% \text { of the implant length from } \\
\text { implant apex. }\end{array}$ \\
\hline
\end{tabular}

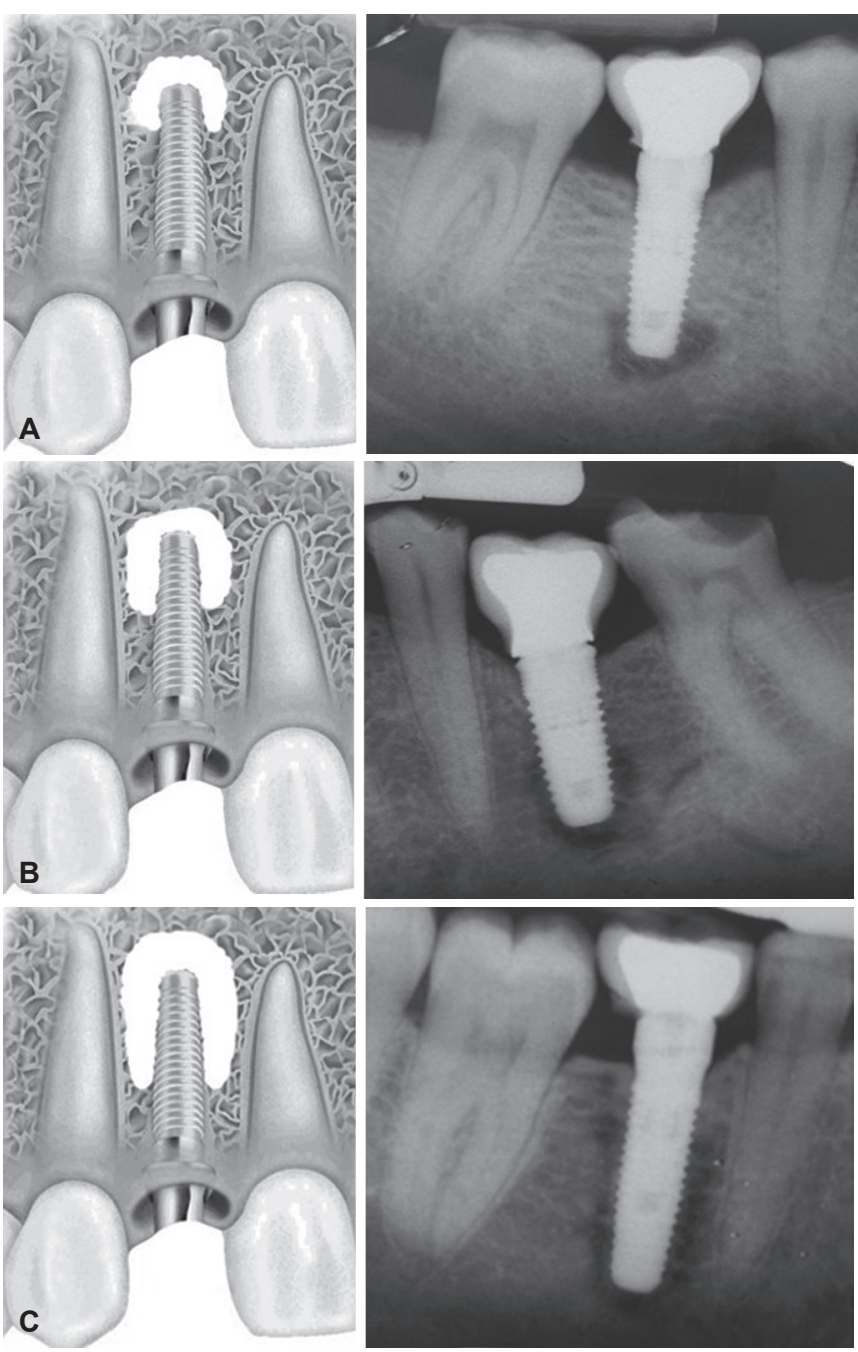

Figs 2A to C: Figure demonstrating the various proposed classes for retrograde peri-implantitis (RPI): (A) Class I mild RPI (bone loss $<25 \%$ of implant length from implant apex), (B) class II moderate RPI (bone loss $25-50 \%$ of implant length from implant apex), and (C) Class III advanced RPI (bone loss $>50 \%$ of implant length from implant apex)

\section{DISCUSSION}

Implant dentistry is becoming widely accepted as a routine treatment modality. With the increase in the number of implants being placed, cases of RPI are not as rare as they were once. Retrograde peri-implantitis has been attributed to a large number of etiologies including bone overheating, poor bone quality, drilling beyond implant length, contamination during insertion, bone microfractures secondary to premature loading, and implant insertion in a site with existing inflammation, such as apical periodontitis. However, the current consensus is that the etiology for RPI is primarily bacterial in nature and other factors may act as secondary complicating factors. ${ }^{30}$ The diagnosis of RPI is based on clinical signs and symptoms and radiographic findings. The clinical manifestations of RPI include pain, inflammation, fistula formation, and swelling or in advanced cases implant mobility. ${ }^{31}$ The clinical features may not clearly indicate/ 
corelate with the actual extent of the lesion. Radiographic features include a radiolucency surrounding or including the implant apex with relatively normal marginal bone. ${ }^{31}$

This article introduces a simple and descriptive classification for RPI. The interprofessional communication can be benefited from such a classification system, which clearly differentiates lesions based on their severity. A well-accepted classification has the advantages of facilitating communication, improved understanding of the nature, and response of the treated cases. The proposed classification takes into consideration the radiographic extent of peri-implant bone loss. The rationale of classification was to give a clear clinical distinction of various stages, treatment suggestions, and prognosis.

Unlike periodontitis and peri-implantitis, the RPI lesion is not amenable to clinical examination like probing and even may not show telltale clinical signs. The clinical features are not definite or omnipresent and vary greatly. ${ }^{31}$ Sometimes, the lesion may be asymptomatic. Although radiographic changes may not be present in the acute initial stages, the late and symptomatic stages always demonstrate the presence of an apical radiolucency. ${ }^{31}$ Hence, radiographic features were taken as the basis of this classification.

A standardized periapical radiograph can give accurate values of the amount of bone loss around the implant apex; however, owing to the vast variety of shapes and morphology of implants, absolute values may be difficult to compare among different implants. Hence, the present classification is proposed based on the percentage bone loss relative to the length of the implant. A standardized radiograph immediately after implant placement may provide details about the baseline relationship of bone-to-implant apex and facilitate comparison with the later radiographs to assess the extent of bone that has been lost during the given time period.

The previous classification by Reiser and Nevins ${ }^{8}$ proposed that the inactive form was actually an apical scar which could have resulted from a residual bone cavity created while placing an implant that was shorter than the osteotomy. The active or infected form was explained as occurring when an implant apex was placed in close proximity to an existing infection or placement of contaminated implant or that resulting from bone necrosis caused by overheating during preparation. The authors suggested that the inactive type of RPI should be observed and monitored whereas the infected type required surgical intervention, elimination of the infection, and reception of apical part of implant or implant removal depending on the extent of the infection and the stability of the implant. This classification is based on the lesion activity and does give treatment guidelines. However, it does not differentiate between the treatment modalities on the basis of extent of bone involvement.

The classification of RPI by Sussman ${ }^{9}$ describes two types of RPI, i.e., Type 1: Implant to tooth caused due to a direct or indirect trauma caused to the adjacent tooth during osteotomy preparation. A type 2 lesion is described as tooth to implant in which there is spread of infection from an endodontically involved tooth to adjacent implant. This classification gives an idea about the etiology of the RPI lesion. It does not give any information regarding the degree of bone destruction around the implant. Also it does not provide any overview of the prognosis or guidelines for the type of treatment to be rendered in specific cases.

Peñarrocha-Diago et al classified the RPI lesion according to the stages of involvement. The first stage was the acute non-suppurated apical peri-implantitis characterized by redness, swelling, and acute pain but no radiographic features. The second stage was acute suppurated apical peri-implantitis, which has similar clinical features as the first stage along with a radiolucent lesion at the implant apex. The next stage was subacute or suppurated fistulized apical peri-implantitis, which is characterized by dull pain and mild swelling and redness along with defined periapical radiolucency, which may continue as marginal bone loss. For the first two stages, periapical surgery was suggested, whereas for the third stage, surgery was suggested in the absence of implant mobility. In this classification, treatment guidelines are provided, but the extent of involvement of the lesion was not considered.

The PIST classification has been proposed by Kadkhodazadeh and Amid for peri-implant, periodontal, and periapical lesions. It is an etiology-based classification. The classes relating to apical peri-implantitis are $\mathrm{P}-1$, which is primary periodontitis in adjacent tooth and secondary involvement of implant. In P-3 there is primary periodontitis in adjacent tooth and marginal and periapical implantitis. In class I-1 it is primarily apical peri-implant lesion, which may involve the apical part of adjacent tooth secondarily. In the S-1 lesion, apical lesions are seen on both implant and adjacent tooth but they occur independently of each other. In S-3 there are apical and marginal lesions on both implant and natural tooth, also occurring separately from each other. T-0 is an asymptomatic periapical lesion involving implant and/or adjacent tooth, whereas T-1 is a symptomatic periapical lesion involving implant and/or adjacent tooth. This classification is comprehensive; however, it does not provide any treatment indications.

In the current classifications, no quantification of bone loss, prognosis, or case-specific treatment indications are outlined clearly. Some cases can occur as an overlap in 
two stages. To overcome the shortcomings of the present classifications, this classification is being proposed. The chances of overlap are minimum and the degree of bone loss can be clearly assessed. When assessed for interobserver agreement, the scores were interpreted as good. Hence, it can be said that it is easy and reproducible and has good interexaminer reliability. To the best of our knowledge, this is the first attempt at classifying RPI quantitatively according to the radiographic amount of bone destruction seen.

On performing literature search, the authors found 56 published reports on RPI. This demonstrates the relatively low frequency of occurrence of these lesions. The incidence of this lesion may range from 1.6\% in the maxilla to $2.7 \%$ in the mandible. ${ }^{6}$ To create a classification, sufficient data should be assessed for it to be comprehensive and universally applicable. Hence, the authors collected all available high-quality IOPA from the published literature on which the proposed classification was based.

Majority of the IOPAs examined by the authors fell in class II as per the proposed classification. This can be attributed to the fact that an unchecked lesion progresses from class I to III over a period of time. A class I lesion is an early mild lesion and may not be often diagnosed. A class III lesion is too advanced, may frequently be associated with implant mobility, and hence may be explanted. Such cases may not be reported as frequently as their successfully managed counterparts. A class II lesion is more successfully managed when detected.

Chan et $\mathrm{al}^{15}$ have proposed a decision tree for the management of RPI. According to them, a mobile implant must be explanted; symptomatic immobile implant should be managed by surgical intervention. For lesions associated with endodontically involved teeth, the first line of management is to treat the tooth and wait, and if lesion does not resolve, surgical intervention is indicated. However, there is no differentiation between lines of treatment depending on the size of the lesion at the time of diagnosis. A class III or II lesion may require comparatively aggressive and extensive management as compared with a class I lesion. Another excellent decision tree has been proposed by Park et $\mathrm{al}^{55}$ for the management of RPI. They have considered bone loss less than half the length of implant as adequate osseointegration. For such cases they suggested surgical management of nonendodontically compromised cases. When the bone loss involved more than half the length of implant, osseointegration is considered inadequate and implant is suggested to be removed and new wider implant placement is recommended. They have also classified the bone defect of less than $5 \mathrm{~mm}$ to be managed by membrane placement only, whereas more than $5 \mathrm{~mm}$ to be managed by bone grafting in conjunction with membrane placement. Though the basic distinction is presented for the extent of lesion, the distinction between adequate and inadequate osseointegration is too sudden. This may lead to improper management of borderline cases, and some cases that could be managed surgically can go for explantation.

From the selected articles, the type of treatment done was also recorded. When reviewed in the cases selected, class I and II lesions are most commonly managed with open-flap debridement. This may or may not be followed by placement of bone graft and/or barrier membrane. ${ }^{19,21}$ Also, most of the lesions in these classes tend to show complete resolution. Some of the reports also advocate the apical resection of implant, ${ }^{7}$ but increasing evidence indicates that guided bone regeneration is successful in the management of these cases. When the lesions belonged to class III at the time of diagnosis, the management is frequently more aggressive including open-flap debridement, bone graft, and barrier membrane placement and/or resection of the apical part of the implant. ${ }^{7,13,14,18,51}$ If the lesion does not resolve or the implant is clinically mobile, the implant has to be explanted. ${ }^{36,42,54,55}$ There are also reports of successful implant placement after explantation at the same site. ${ }^{54}$

The pathogenesis of an endodontic lesion is remarkably similar to periodontitis and peri-implantitis in terms of involved chemical mediators and responses at the host cellular level. ${ }^{96}$ However, the healing potential of an endodontic lesion is quite high as compared with a periodontitis or conventional peri-implantitis. It has been observed that following the treatment, resolution of the apical radiolucency is observed in most of the cases. This has been attributed to the fact that after completion of the therapy, a closed environment is obtained and healing occurs relatively undisturbed. ${ }^{96}$ Similarly, RPI is a closed lesion. Once the nidus of infection is removed by open-flap debridement, a completely closed environment is achieved. The healing potential of such lesions after intervention may be similarly higher than in conventional peri-implantitis, where the crestal bone is involved. This justifies the finding in the literature that even after advanced bone involvement such as in proposed class III there are chances of complete resolution of the lesion. ${ }^{19}$

Based on the above observations and two previously published treatment algorithms, a modified decision tree has been proposed. Apart from the etiology, it also considers the extent of the lesion and gives treatment suggestions based on it (Flow Chart 2). Once the diagnosis of RPI is established, the clinician must differentiate it as either a primary implant lesion or a lesion arising endodontically 
Flow Chart 2: Decision tree and prognosis for mild, moderate, and advanced classes of RPI ${ }^{15,55}$

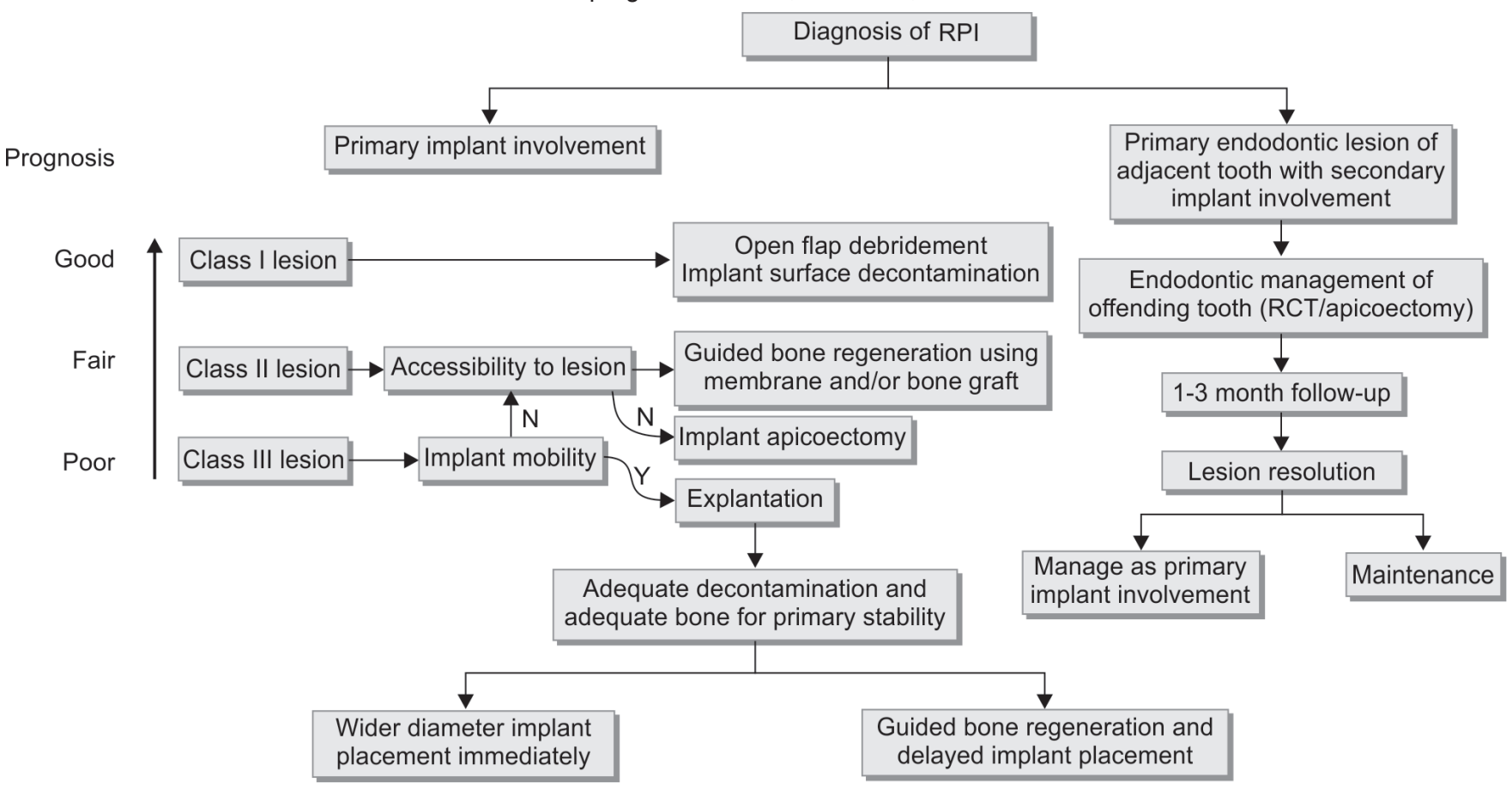

in adjacent tooth and involving implant secondarily. If the lesion is primary, it should be classified into class I, II, or III. A class I lesion can be managed by open-flap debridement and it can be followed by implant surface decontamination. A class II lesion has to be assessed for accessibility. Open-flap debridement followed by guided bone regeneration using barrier membranes and / or bone graft is suggested when accessibility to the lesion is good. In case of poor accessibility, open-flap debridement followed by resection of apical part of implant, followed by guided bone regeneration using barrier membranes and / or bone graft, is suggested. A class III lesion demonstrates advanced bone loss, and hence, the implant mobility must be assessed. If mobility is absent, the treatment should be done similar to a class II lesion; however, if implant mobility is seen, explantation should be performed. After explantation, if sufficient bone remains to achieve good implant stability and the decontamination of the site is thorough, immediate wide diameter implant placement can be done. However, if sufficient bone is not present, guided bone regeneration followed by delayed implant placement has to be followed.

If the lesion is secondary to primary endodontic lesion from an adjacent tooth, endodontic management of the offending tooth should be performed. This should be followed up for up to 1 to 3 months. Closed endodontic lesions have high healing potential and demonstrate complete resolution of periapical lesion. ${ }^{96}$ If resolution occurs, the patient should be kept under monitoring. If the lesion shows no sign of resolution or shows signs of progressing, it should now be managed as a primary implant lesion.
Also, from the reviewed articles it was noted that most of the lesions in classes I and II tend to show complete resolution. ${ }^{13,14,18,19,21}$ The prognosis can be considered fair to good. The resolution frequency of class III lesions is lower than that of class I and II lesions. The prognosis can be from fair to poor (in case of mobility). ${ }^{36,42,54,55}$ To the best of our knowledge, this is the first classification that comments on the prognosis based on the extent of the lesion of RPI.

This classification can be used in the formulation of sophisticated standardized treatment algorithms. Such algorithms guide clinicians, so as to decide which treatment modality to follow when faced by a particular clinical scenario. It may be helpful to clinicians managing cases of RPI, the treatment of which still remains highly empirical. As our knowledge about the pathogenesis of RPI increases, modifications of this classification may be suggested.

\section{CONCLUSION}

This classification quantifies and describes peri-implant apical bone loss in an objective and reproducible manner. The proposed classification can be applied for standardization purposes in research methodologies so as to have a reliable comparison of the initial lesion and compare the treatment outcomes in different studies with similar aims. Further research is required to analyze the validity of this proposed classification.

\section{REFERENCES}

1. Mombelli A, Van Oosten MA, Schurch E Jr, Land NP. The microbiota associated with successful or failing osseointegrated titanium implants. Oral Microbiol Immunol 1987 Dec;2(4):145-151. 
2. Froum SJ, Rosen PS. A proposed classification for periimplantitis. Int J Periodont Restor Dent 2012 Oct;32(5):533-540.

3. Jovanovic SA. Diagnosis and treatment of peri-implant disease. Curr Opin Periodontol 1994;2:194-204.

4. Spiekerman, H. Atlas de Implantología. Barcelona: Editorial Masson; 1995.

5. McAllister BS, Masters D, Meffert RM. Treatment of implants demonstrating periapical radiolucencies. Pract Periodontics Aesthet Dent 1992 Nov-Dec;4(9):37-41.

6. Quirynen M, Vogels R, Alsaadi G, Naert I, Jacobs R, van Steenberghe D. Predisposing conditions for retrograde periimplantitis, and treatment suggestions. Clin Oral Implants Res 2005 Oct;16(5):599-608.

7. Balshi SF, Wolfinger GJ, Balshi TJ. A retrospective evaluation of a treatment protocol for dental implant periapical lesions: long-term results of 39 implant apicoectomies. Int J Oral Maxillofac Implants 2007 Mar-Apr;22(2):267-272.

8. Reiser GM, Nevins M. The implant periapical lesion: etiology, prevention, and treatment. Compend Contin Educ Dent 1995 Aug;16(8):768, 770, 772.

9. Sussman HI. Periapical implant pathology. J Oral Implantol 1998;24(3):133-138.

10. Peñarrocha-Diago M, Maestre-Ferrín L, Cervera-Ballester J, Peñarrocha-Oltra D. Implant periapical lesion: diagnosis and treatment. Med Oral Patol Oral Cir Bucal 2012 Nov 1;17(6): e1023-e1027.

11. Kadkhodazadeh M, Amid R. A new classification for the relationship between periodontal, periapical, and peri-implant complications. Iran Endod J 2013 Summer;8(3):103-108.

12. Armitage GC. Periodontal diseases: diagnosis. Ann Periodontol 1996 Nov;1(1):37-215.

13. Quaranta A, Andreana S, Pompa G, Procaccini M. Active implant peri-apical lesion: a case report treated via guided bone regeneration with a 5-year clinical and radiographic follow-up. J Oral Implantol 2014 Jun;40(3):313-319.

14. Mohamed JB, Alam MN, Singh G, Chandrasekaran SC. The management of retrograde peri-implantitis: a case report. J Clin Diagn Res 2012 Nov;6(9):1600-1602.

15. Chan HL, Wang HL, Bashutski JD, Edwards PC, Fu JH, Oh TJ. Retrograde peri-implantitis: a case report introducing an approach to its management. J Periodontol 2011 Jul;82(7): 1080-1088.

16. Mohamed JB, Shivakumar B, Sudarsan S, Arun KV, Kumar TS. Retrograde peri-implantitis. J Indian Soc Periodontol 2010 Jan;14(1):57-65.

17. Waasdorp J, Reynolds M. Nonsurgical treatment of retrograde peri-implantitis: a case report. Int J Oral Maxillofac Implants 2010 Jul-Aug;25(4):831-833.

18. Dahlin C, Nikfarid H, Alsén B, Kashani H. Apical periimplantitis: possible predisposing factors, case reports, and surgical treatment suggestions. Clin Implant Dent Relat Res 2009 Sep;11(3):222-227.

19. Ataullah K, Chee LF, Peng LL, Lung HH. Management of retrograde peri-implantitis: a clinical case report. J Oral Implantol 2006;32(6):308-312.

20. Tözüm TF, Sençimen M, Ortako lu K, Ozdemir A, Aydin OC, Kele M. Diagnosis and treatment of a large periapical implant lesion associated with adjacent natural tooth: a case report. Oral Surg Oral Med Oral Pathol Oral Radiol Endod 2006 Jun;101(6):e132-e138.

21. Flanagan D. Apical (retrograde) peri-implantitis: a case report of an active lesion. J Oral Implantol 2002;28(2):92-96.
22. Ayangco L, Sheridan PJ. Development and treatment of retrograde peri-implantitis involving a site with a history of failed endodontic and apicoectomy procedures: a series of reports. Int J Oral Maxillofac Implants 2001 May-Jun;16(3):412-417.

23. Bretz WA, Matuck AN, de Oliveira G, Moretti AJ, Bretz WA. Treatment of retrograde peri-implantitis: clinical report. Implant Dent 1997 Winter;6(4):287-290.

24. Truninger TC, Philipp AO, Siegenthaler DW, Roos M, Hämmerle $\mathrm{CH}$, Jung RE. A prospective, controlled clinical trial evaluating the clinical and radiological outcome after 3 years of immediately placed implants in sockets exhibiting periapical pathology. Clin Oral Implants Res 2011 Jan;22(1): 20-27.

25. Nguyen-Hieu T, Borghetti A, Aboudharam G. Peri-implantitis: from diagnosis to therapeutics. J Investig Clin Dent 2012 May;3(2):79-94.

26. Zhou W, Han C, Li D, Li Y, Song Y, Zhao Y. Endodontic treatment of teeth induces retrograde peri-implantitis. Clin Oral Implants Res 2009 Dec;20(12):1326-1332.

27. Meffert RM. Maintenance and treatment of the ailing and failing implant. J Indiana Dent Assoc 1994 Fall;73(3):22-24.

28. Meffert RM. Treatment of failing dental implants. Curr Opin Dent 1992 Mar;2:109-114.

29. Kahler B. Healing of a cyst-like lesion involving an implant with nonsurgical management. J Endod 2015 May;41(5): 749-752.

30. Feller L, Jadwat $Y$, Chandran R, Lager I, Altini M, Lemmer J. Radiolucent inflammatory implant periapical lesions: a review of the literature. Implant Dent 2014 Dec;23(6):745-752.

31. Temmerman A, Lefever D, Teughels W, Balshi TJ, Balshi SF, Quirynen M. Etiology and treatment of periapical lesions around dental implants. Periodontol 20002014 Oct;66(1): 247-254.

32. Kutlu HB, Genc T, Tozum TF. Treatment of refractory apical peri-implantitis: a case report. J Oral Implantol 2016 Feb;42(1):104-109.

33. Buhara O, Uyanık LO, Ayalı A, Aydın M. Active implant periapical lesions leading to implant failure: two case reports. J Oral Implantol 2014 Jun;40(3):325-329.

34. Qu C, Meng H, Han J. Implant periapical lesion - a review and a case report with histological evaluation. Clin Oral Implants Res 2014 Sep;25(9):1099-1104.

35. Peñarrocha-Diago M, Maestre-Ferrín L, Penarrocha-Oltra D, Canullo L, Piattelli A, Peñarrocha-Diago M. Inflammatory implant periapical lesion prior to osseointegration: a case series study. Int J Oral Maxillofac Implants 2013 Jan-Feb;28(1): 158-162.

36. Lefever D, Van Assche N, Temmerman A, Teughels W, Quirynen M. Etiology, microbiology and therapy of periapical lesions around oral implants: a retrospective analysis. J Clin Periodontol 2013 Mar;40(3):296-302.

37. Esfahrood ZR, Kadkhodazadeh M, Amid R, Rokn A. Is the periapical lesion a risk for periimplantitis? (A review). J Dent 2012 Spring;9(2):162-173.

38. Fugazzotto P. A retrospective analysis of immediately placed implants in 418 sites exhibiting periapical pathology: results and clinical considerations. Int J Oral Maxillofac Implants 2012 Jan-Feb;27(1):194-202.

39. Zhou Y, Cheng Z, Wu M, Hong Z, Gu Z. Trepanation and curettage treatment for acute implant periapical lesions. Int $J$ Oral Maxillofac Surg 2012 Feb;41(2):171-175. 
40. Beitlitum L, Artzi Z, Tsesis I, Nemcovsky CE. Clinical dilemmas concerning immediate implants in the esthetic zone. Refuat Hapeh Vehashinayim (1993) 2011 Jan;28(1): 20-30,77.

41. Chang LC, Hsu CS, Lee YL. Successful medical treatment of an implant periapical lesion: a case report. Chang Gung Med J 2011 Jan-Feb;34(1):109-114.

42. Silva GC, Oliveira DR, Vieira TC, Magalhães CS, Moreira AN. Unusual presentation of active implant periapical lesions: a report of two cases. J Oral Sci 2010 Sep;52(3):491-494.

43. Romanos GE, Froum S, Costa-Martins S, Meitner S, Tarnow DP. Implant periapical lesions: etiology and treatment options. J Oral Implantol 2011;37(1):53-63.

44. Merheb J, Coucke W, Jacobs R, Naert I, Quirynen M. Influence of bony defects on implant stability. Clin Oral Implants Res 2010 Sep;21(9):919-923.

45. Naves MM, Horbylon BZ, Gomes CF, Menezes HH, Bataglion C, Magalhães DD. Immediate implants placed into infected sockets: a case report with 3-year follow-up. Braz Dent J 2009;20(3):254-258.

46. Rosendahl K, Dahlberg G, Kisch J, Nilner K. Implant periapical lesion. A case series report. Swed Dent J 2009;33(2):49-58.

47. Favia G, Piattelli A, Sportelli P, Capodiferro S, Iezzi G. Osteonecrosis of the posterior mandible after implant insertion: a clinical and histological case report. Clin Implant Dent Relat Res 2011 Mar;13(1):58-63.

48. Peñarrocha-Diago M, Boronat-Lopez A, García-Mira B. Inflammatory implant periapical lesion: etiology, diagnosis, and treatment - presentation of 7 cases. J Oral Maxillofac Surg 2009 Jan;67(1):168-173.

49. Rokadiya S, Malden NJ. An implant periapical lesion leading to acute osteomyelitis with isolation of Staphylococcus aureus. Br Dent J 2008 Nov;205(9):489-491.

50. Steiner DR. The resolution of a periradicular lesion involving an implant. J Endod 2008 Mar;34(3):330-335.

51. Nedir R, Bischof M, Pujol O, Houriet R, Samson J, Lombardi T. Starch-induced implant periapical lesion: a case report. Int J Oral Maxillofac Implants 2007 Nov-Dec;22(6): 1001-1006.

52. Lin S, Mayer Y. Treatment of a large periradicular lesion of endodontic origin around a dental implant with enamel matrix protein derivative. J Periodontol 2007 Dec;78(12):2385-2388.

53. Casap N, Zeltser C, Wexler A, Tarazi E, Zeltser R. Immediate placement of dental implants into debrided infected dentoalveolar sockets. J Oral Maxillofac Surg 2007 Mar;65(3):384-392.

54. Tseng CC, Chen YH, Pang IC, Weber HP. Peri-implant pathology caused by periapical lesion of an adjacent natural tooth: a case report. Int J Oral Maxillofac Implants 2005 Jul-Aug;20(4):632-635.

55. Park SH, Sorensen WP, Wang HL. Management and prevention of retrograde peri-implant infection from retained root tips: two case reports. Int J Periodont Restor Dent 2004 Oct;24(5):422-433.

56. Shabahang S, Bohsali K, Boyne PJ, Caplanis N, Lozada J, Torabinejad M. Effect of teeth with periradicular lesions on adjacent dental implants. Oral Surg Oral Med Oral Pathol Oral Radiol Endod 2003 Sep;96(3):321-326.

57. Oh TJ, Yoon J, Wang HL. Management of the implant periapical lesion: a case report. Implant Dent 2003;12(1):41-46.

58. Scarano A, Di Domizio P, Petrone G, Iezzi G, Piattelli A. Implant periapical lesion: a clinical and histologic case report. J Oral Implantol 2000;26(2):109-113.
59. Jalbout ZN, Tarnow DP. The implant periapical lesion: four case reports and review of the literature. Pract Proced Aesthet Dent 2001 Mar;13(2):107-112.

60. Piattelli A, Scarano A, Balleri P, Favero GA. Clinical and histologic evaluation of an active "implant periapical lesion": a case report. Int J Oral Maxillofac Implants 1998 Sep-Oct;13(5):713-716.

61. Piattelli A, Scarano A, Piattelli M, Podda G. Implant periapical lesions: clinical, histologic, and histochemical aspects. A case report. Int J Periodont Restor Dent 1998 Apr;18(2):181-187.

62. Sussman HI. Endodontic pathology leading to implant failurea case report. J Oral Implantol 1997;23(3):112-115.

63. Flanagan D. Implant placement in failed endodontic sites: a review. J Oral Implantol 2016 Apr;42(2):224-230.

64. Langer L, Langer B, Salem D. Unintentional root fragment retention in proximity to dental implants: a series of six human case reports. Int J Periodont Restor Dent 2015 May-Jun;35(3):305-313.

65. Verdugo F, Castillo A, Simonian K, Castillo F, Farez-Vidal E, D'Addona A. Periodontopathogen and Epstein-Barr virus-associated periapical periodontitis maybe the source of retrograde infectious peri-implantitis. Clin Implant Dent Relat Res 2015 Feb;17(1):199-207.

66. Martins JN, Freitas F, Andre S, Moreira A, Carames J. Very large inflammatory odontogenic cyst with origin on a single long time traumatized lower incisor. J Clin Diagn Res 2015 Jul;9(7):ZD07-ZD10

67. Hegde R, Krishna Prasad D, Shetty DV, Shetty M. Immediate placement and restoration of implant in periapical infected site in the maxillary esthetic zone: a case report. J Indian Prosthodont Soc 2014 Dec;14(Suppl 1):299-302.

68. Bassi F, Poli PP, Rancitelli D, Signorino F, Maiorana C. Surgical treatment of peri-implantitis: a 17-year follow-up clinical case report. Case Rep Dent 2015;2015:574676.

69. Wolgin M, Tschoppe P, Kielbassa AM. Conservative, surgical, and prosthetic treatment of a patient with a periapical lesion associated with an atypical intraoral sinus tract. Case Rep Dent 2015;2015:495206.

70. Lee CT, Chuang SK, Stoupel J. Survival analysis and other clinical outcomes of immediate implant placement in sites with periapical lesions: systematic review. Int J Oral Maxillofac Implants 2015 Mar-Apr;30(2):268-278.

71. Rosa AC, Francischone CE, Cardoso Mde A, Alonso AC, Filho LC, da Rosa JC. Post-traumatic treatment of maxillary incisors by immediate dentoalveolar restoration with long-term follow-up. Compend Contin Educ Dent 2015 Feb;36(2):130-134.

72. Borgonovo AE, Rigaldo F, Battaglia $\mathrm{D}, \mathrm{Re} \mathrm{D}$, Giannì $\mathrm{AB}$. Digital device in postextraction implantology: a clinical case presentation. Case Rep Dent 2014;2014:327368.

73. Sübay RK, Sübay MO, Balkaya CM. Intentional replantation of a mandibular canine with multiple iatrogenic endodontic complications. Oral Health Dent Manag 2014 Sep;13(3):811-814.

74. Peñarrocha-Diago MA, Aloy-Prósper A, Peñarrocha-Oltra $\mathrm{D}$, Peñarrocha-Diago M. Replantation of a maxillary second molar after removal of a third molar with a dentigerous cyst: case report and 12-month follow-up. J Clin Exp Dent 2014 Apr 1;6(2):e185-e188.

75. Asgary S, Nosrat A. Concurrent intentional replantation of maxillary molars using a novel root-end filling. Gen Dent 2014 May-Jun;62(3):30-33.

76. Montoya-Salazar V, Castillo-Oyagüe R, Torres-Sánchez C, Lynch CD, Gutiérrez-Pérez JL, Torres-Lagares D. Outcome of 
single immediate implants placed in post-extraction infected and non-infected sites, restored with cemented crowns: a 3-year prospective study. J Dent 2014 Jun;42(6):645-652.

77. Yamazaki S, Arakawa H, Maekawa K, Noda K, Hara ES, Minakuchi H, Sonoyama W, Matsuka Y, Kuboki T. A retrospective comparative 8-year study of cumulative complications in teeth adjacent to both natural and implantsupported fixed partial dentures. Int J Prosthodont 2013 May-Jun;26(3):260-264.

78. Kim JE, Shim JS, Huh JB, Rim JS, Lee JY, Shin SW. Altered sensation caused by peri-implantitis: a case report. Oral Surg Oral Med Oral Pathol Oral Radiol 2013 Jul;116(1):e9-e13.

79. Sun CX, Henkin JM, Ririe C, Javadi E. Implant failure associated with actinomycosis in a medically compromised patient. J Oral Implantol 2013 Apr;39(2):206-209.

80. Chou YH, Du JK, Chou ST, Hu KF, Tsai CC, Ho KY, Wu YM, Ho YP. An interdisciplinary treatment approach combining orthodontic forced eruption with immediate implant placement to achieve a satisfactory treatment outcome: a case report. Clin Implant Dent Relat Res 2013 Feb;15(1):113-120.

81. Krithika C, Kota S, Gopal KS, Koteeswaran D. Mixed periapical lesion: differential diagnosis of a case. Dentomaxillofac Radiol 2011 Mar;40(3):191-194.

82. ParkJB. Healing of extraction socket grafted with deproteinized bovine bone and acellular dermal matrix: histomorphometric evaluation. Implant Dent 2010 Aug;19(4):307-313.

83. Bornstein MM, Wiest R, Balsiger R, Reichart PA. Anterior Stafne's bone cavity mimicking a periapical lesion of endodontic origin: report of two cases. J Endod 2009 Nov;35(11):1598-1602.

84. Tyndall DA, Rathore S. Cone-beam CT diagnostic applications: caries, periodontal bone assessment, and endodontic applications. Dent Clin North Am 2008 Oct;52(4):825-841.

85. Casado PL, Donner M, Pascarelli B, Derocy C, Duarte ME, Barboza EP. Immediate dental implant failure associated with nasopalatine duct cyst. Implant Dent 2008 Jun;17(2):169-175.

86. Schwartz-Arad D, Levin L. Post-traumatic use of dental implants to rehabilitate anterior maxillary teeth. Dent Traumatol 2004 Dec;20(6):344-347.

87. Eratalay K, Demiralp B, Akincibay H, Tözüm TF. Localized edentulous ridge augmentation with upside down osteo- tomy prior to implant placement. Dent Traumatol 2004 Oct;20(5):300-304.

88. Reiser GM, Manwaring JD, Damoulis PD. Clinical significance of the structural integrity of the superior aspect of the mandibular canal. J Periodontol 2004 Oct;75(2):322-326.

89. Bencharit S, Schardt-Sacco D, Zuniga JR, Minsley GE. Surgical and prosthodontic rehabilitation for a patient with aggressive florid cemento-osseous dysplasia: a clinical report. J Prosthet Dent 2003 Sep;90(3):220-224.

90. Hosny M, Duyck J, van Steenberghe D, Naert I. Within-subject comparison between connected and nonconnected toothto-implant fixed partial prostheses: up to 14-year follow-up study. Int J Prosthodont 2000 Jul-Aug;13(4):340-346.

91. Horton RA, Ludlow JB, Webber RL, Gates W, Nason RH Jr, Reboussin D. Detection of peri-implant bone changes with axial tomosynthesis. Oral Surg Oral Med Oral Pathol Oral Radiol Endod 1996 Jan;81(1):124-129.

92. Kenney EB, Lekovic V, Han T, Carranza FA Jr, Dimitrijevic B. The use of a porous hydroxylapatite implant in periodontal defects. I. Clinical results after six months. J Periodontol 1985 Feb;56(2):82-88.

93. Kwon EY, Cho Y, Lee JY, Kim SJ, Choi J. Endodontic treatment enhances the regenerative potential of teeth with advanced periodontal disease with secondary endodontic involvement. J Periodontal Implant Sci 2013 Jun;43(3): 136-140.

94. Tözüm TF, Sençimen M, Ortako lu K, Ozdemir A, Aydin OC, Kele M. Diagnosis and treatment of a large periapical implant lesion associated with adjacentnatural tooth: a case report. Oral Surg Oral Med Oral Pathol Oral Radiol Endod 2006 Jun;101(6):e132-e138.

95. Jung RE, Zaugg B, Philipp AO, Truninger TC, Siegenthaler DW, Hämmerle $\mathrm{CH}$. A prospective, controlled clinical trial evaluating the clinical radiological and aesthetic outcome after 5 years of immediately placed implants in sockets exhibiting periapical pathology. Clin Oral Implants Res 2013 Aug; 24(8):839-846.

96. Nair PN. Pathogenesis of apical periodontitis and the causes of endodontic failures. Crit Rev Oral Biol Med 2004 Nov 1; 15(6):348-381. 